\title{
Amidourea-based homoduplex as a super organogelator
}

\author{
CHU WeiJun ${ }^{1,2}$ \& CHEN ChuanFeng ${ }^{1 *}$ \\ ${ }^{1}$ Beijing National Laboratory for Molecular Sciences, CAS Key Laboratory of Molecular Recognition and Function, Institute of Chemistry, \\ Chinese Academy of Sciences, Beijing 100190, China; \\ ${ }^{2}$ Graduate University of Chinese Academy of Sciences, Beijing 100049, China
}

Received April 11, 2012; accepted May 23, 2012; published online September 14, 2012

\begin{abstract}
The amidourea-based homoduplex was developed as a super organogelator, which could form stable gels in wide-tested solvents. And the reversible gel to solution transition was responsive to heat/cool and acid/base stimuli. The organogels were extensively investigated by ${ }^{1} \mathrm{H} \mathrm{NMR}, \mathrm{UV}$-visible absorption spectroscopy, fluorescence spectroscopy, scanning electron microscopy, transmission electron microscopy and powder X-ray diffraction. Based on these data, the gelation mechanism was rationally proposed. The hydrogen-bonded homoduplexes served as the basic assembling units, and further aggregated into three dimensional networks via $\pi-\pi$ stacking and van der Waals interactions, which consequently led to the entangled fibers for the gel formation.
\end{abstract}

amidourea, homoduplex, organogelator, gelation mechanism

Citation: Chu W J, Chen C F. Amidourea-based homoduplex as a super organogelator. Chin Sci Bull, 2012, 57: 4278-4283, doi: 10.1007/s11434-012-5440-4

Gels are well-known soft materials with daily applications, such as hair gel, contact lenses, gelatin desserts, lithium grease and so on. Among them, one of the most emerging categories is organogels, which are composed of a selfassembled supramolecular structure of low-molecular-mass organic gelators (LMOGs) and a large volume of organic liquids immobilized therein [1-3]. Over the past decade, dramatically increased attention has been focused on the organogels [4], due to their widespread potential applications in sensors [5], photonics [6], electronic devices, regenerative medicine [7], catalysis [8], cosmetics and many other fields [2-4]. A number of compounds with diverse structures have been developed as LMOGs, including steroids $[9,10]$, triterpenoids [11,12], amino acids [13-15], hydrazide [16-20], urea derivatives [21-23], and $\pi$-systems and chromophores [24-27]. In particular, many LMOGs have been developed as smart gel systems that are responsive to stimuli, such as ions [28,29], molecules [30,31], pH $[32,33]$, redox [34,35], light [36,37], electric field [38], and ultrasound $[39,40]$.

Generally, organogels are formed by LMOGs self-

*Corresponding author (email: cchen@iccas.ac.cn) assembling into reticular three-dimensional networks with solvent molecules entrapped inside through non-covalent interactions. However, the gelation mechanism on the molecular level is elusive, and a rational correlation of molecular structure and gelation ability in a given solvent still remains a challenge. The development of new LMOG with a well-understood gelation mechanism will provide valuable insights into the gelation process, and thus may promote the rational design of organogelators. Recently, hydrogen-bonded molecular duplexes based on the hydrazide [18] and amide [41] units are reported as LMOGs, but both of them gelate only in several apolar solvents.

As a continuation of our previous work on the amidourea-based hydrogen-bonded molecular duplexes [42], we herein report the amidourea-based homoduplex (Figure 1) as a super LMOG, which form stable gels in wide-tested solvents. And the reversible gel to solution transition is responsive to heat/cool and acid/base stimuli. Moreover, we investigated the organogels of $\mathbf{1}$ via ${ }^{1} \mathrm{H}$ NMR, UV-visible absorption spectroscopy, fluorescence spectroscopy, scanning electron microscopy (SEM), transmission electron microscopy (TEM) and powder X-ray diffraction (PXRD), and attempted to explore the gelation mechanism. 


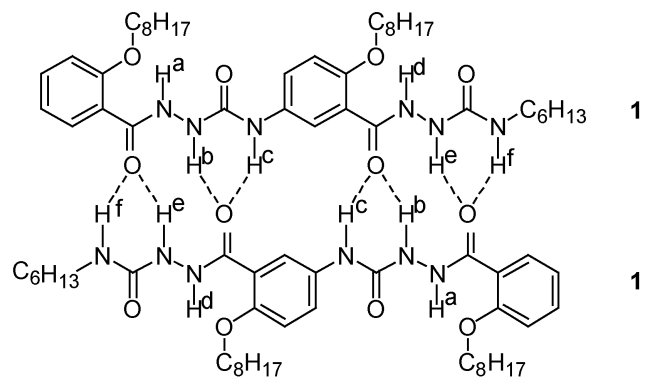

Figure 1 Amidourea-based homoduplex 1·1 with proton-labeling.

\section{Experimental}

\subsection{General methods}

${ }^{1} \mathrm{H}$ NMR spectra were recorded on Bruker DMX 300 Spectrometer. UV-visible absorption spectra were measured on a UV 2041PC Shimadzu photometer. Fluorescence spectra were measured on a Hitachi F-4500 spectrometer. The morphologies of the xerogels were characterized by SEM. TEM was performed on a JEOL JEM-2011 microscope. XRD data were collected on a Rigaku D/MAX-2500 X-ray diffractometer at a scanning rate of $2 \% \mathrm{~min}$ in the $2 \theta$ range of $2^{\circ}-60^{\circ}$ with $\mathrm{Cu} \mathrm{K \alpha}$ radiation $(\lambda=1.54056 \AA)$. Gel in $\mathrm{CH}_{2} \mathrm{Cl}_{2}$ was coated on a glass plate and the solvent was free-dried. Then the glass plate with xerogel was fixed on a sample holder and subjected to XRD analysis at room temperature.

\subsection{Gel formation}

In a typical gelation experiment, a weighed amount of gelator $\mathbf{1}$ and $1.00 \mathrm{~mL}$ solvent were placed in a sealed glass vial, and then heated until the gelator was completely dissolved. The solution was then left for $0.5 \mathrm{~h}$ under ambient conditions, and the gel formation was verified by the "stable to inversion of the test tube" method [11].

\section{Results and discussion}

The gelation ability of $\mathbf{1}$ was examined in various organic solvents by the "stable to inversion of the test tube" method, and the results were summarized in Table 1. It was shown that organogelator 1 could form stable gels in wide-tested solvents, and the gels could remain without any change for more than three months under ambient conditions. We also found that gelator $\mathbf{1}$ formed transparent gels in aromatic solvents, while opaque gels in chloroalkanes, alcohols and cyclic ethers. Then we carefully determined the minimum gelation concentration (MGC) of $\mathbf{1}$ in the tested gelation solvents, which revealed that LMOG 1 possessed very strong gelation ability. Except 1,2-dichloroethane and chloroform, organogels of $\mathbf{1}$ in all the other gelation solvents could be obtained at impressively low concentrations
(0.19 wt\%-0.67 wt\%). Such an ability to gelate solvents at concentrations lower than $1 \mathrm{wt} \%$ is classified as supergelation [2].

The reversible gel to solution phase transition responsive to heat/cool was the intrinsic property of supramolecular gels that occurred by dis-assembly and self-assembly processes, respectively. The thermo-reversibility of organogels of $\mathbf{1}$ was confirmed by repeated heating and cooling for several cycles (Figure 2). Furthermore, we studied the ac$\mathrm{id} /$ base responsive property of the organogel of $\mathbf{1}$. Interestingly, we found that the gel of $\mathbf{1}$ in $\mathrm{CH}_{2} \mathrm{Cl}_{2}$ converted into fluid solution immediately upon the addition of 10 equiv of trifluoroacetic acid (TFA), and the solution could regenerate gel upon the addition of 12 equiv of triethylamine (TEA) after several minutes at room temperature (Figure 2). And the acid/base responsive process of the organogel could be repeated for at least five cycles. Then we investigated the acid/base responsive process by ${ }^{1} \mathrm{H}$ NMR (Figure 3 ). When adding 10 equiv of TFA into the solution of $\mathbf{1}$ in $\mathrm{CDCl}_{3}(5.0$ $\mathrm{mmol} / \mathrm{L}$ ), all the $\mathrm{NH}$ proton signals significantly shifted upfield and broadened, and some NH proton signals even disappeared, which indicated that TFA broke the hydrogen bonds in $\mathbf{1}$ and might thus lead to the disruption of the gel. After adding 12 equiv of TEA, all the NH proton signals returned to their original positions, which suggested that the hydrogen bonds formed again, and the gel could thus be regenerated. These observations indicated that hydrogen bonding was the main driving force in the gel formation of $\mathbf{1}$.

In our previous work [42], we have demonstrated that compound 1 existed as homoduplex 1.1 through eight intermolecular tricenter hydrogen bonds in low polar solvents (Figure 1). The dimerization constant of homoduplex 1·1 still reached up to $4.4 \times 10^{4} \mathrm{~L} / \mathrm{mol}$ in $1 \%$ DMSO- $d_{6} / \mathrm{CDCl}_{3}$

Table 1 Results of gelation tests for $\mathbf{1}$ in various orangic solvents ${ }^{\text {a) }}$

\begin{tabular}{lccc}
\hline \multicolumn{1}{c}{ Solvent } & State & MGC (mmol/L) & MGC (wt\%) \\
\hline Benzene & TG & 4.4 & 0.35 \\
Toluene & TG & 4.1 & 0.33 \\
Xylene & TG & 4.2 & 0.34 \\
Chlorobenzene & TG & 4.0 & 0.25 \\
1,2-Dichlorobenzene & TG & 5.5 & 0.29 \\
$\mathrm{CH}_{2} \mathrm{Cl}_{2}$ & OG & 7.7 & 0.40 \\
$\mathrm{CHCl}_{3}$ & OG & 29.1 & 1.37 \\
1,2-Dichloroethane & OG & 19.6 & 1.10 \\
Methanol & OG & 3.9 & 0.34 \\
Ethanol & OG & 3.6 & 0.32 \\
2-Propanol & OG & 2.1 & 0.19 \\
1,4-Dioxane & OG & 2.8 & 0.19 \\
THF & OG & 8.6 & 0.67 \\
Diethyl ether & I & & \\
Hexane & I & & \\
EtOAc & P & & \\
DMF & $\mathrm{S}$ & & \\
DMSO & $\mathrm{S}$ & & \\
\hline
\end{tabular}

a) TG: transparent gel; OG: opaque gel; S: soluble; I: insoluble; P: precipitate. 


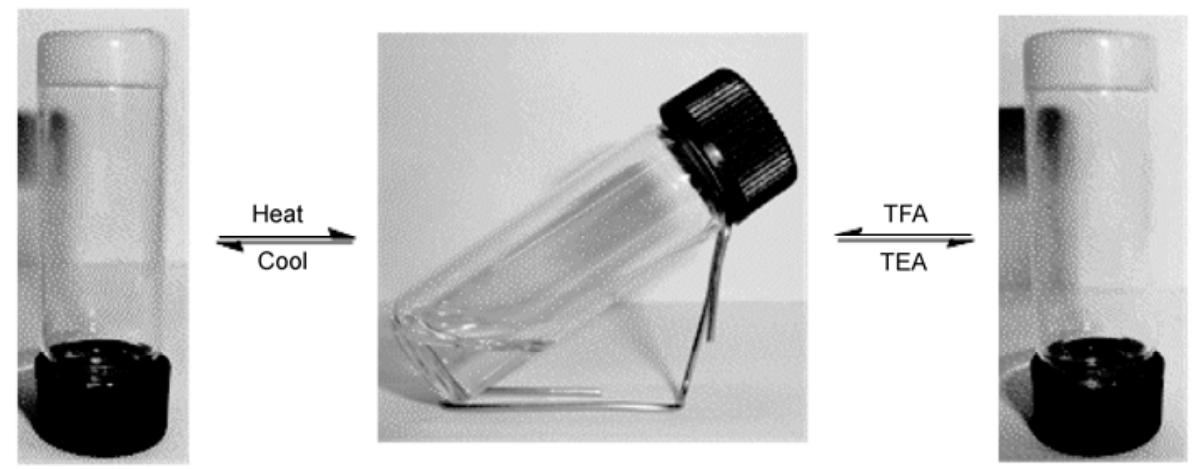

Figure 2 The reversible gel to solution transition of $\mathbf{1}$ in $\mathrm{CH}_{2} \mathrm{Cl}_{2}$ responsive to heat/cool and TFA/TEA.

$(\mathrm{v} / \mathrm{v})$. Thus, it was reasonable to propose that the hydrogen-bonded homoduplexes should serve as the basic units for assembling into supramolecular networks. Compared with individual strands, the duplex structure was significantly rigidified, leading to a well-defined and largely planar surface that should facilitate the further intermolecular aggregation via $\pi-\pi$ stacking interactions and the consequent gel formation. The aggregation of $\mathbf{1}$ in the gel was first evidenced by variable-temperature ${ }^{1} \mathrm{H}$ NMR study of $\mathbf{1}$ in benzene- $d_{6}$ (Figure 4). Compared with the well-resolved ${ }^{1} \mathrm{H} \mathrm{NMR}$ of $\mathbf{1}$ in $\mathrm{CDCl}_{3}$ (Figure 3), the ${ }^{1} \mathrm{H}$ NMR of $\mathbf{1}$ (5.0 $\mathrm{mmol} / \mathrm{L}$ ) in benzene- $d_{6}$ at $298 \mathrm{~K}$ showed almost no peaks because of the gelation. With the temperature increasing, the spectrum became gradually resolved. Above $323 \mathrm{~K}$, the signals of aromatic and $\mathrm{NH}$ protons began to appear, and their intensities increased with the aggregation being weakened via further elevating the temperature. Eventually, a totally well-resolved ${ }^{1} \mathrm{H}$ NMR of $\mathbf{1}$ in benzene- $d_{6}$ was observed above $343 \mathrm{~K}$. These results demonstrated the strong intermolecular aggregation of $\mathbf{1}$ in the gel state.

The self-assembly of $\mathbf{1}$ in the gel was then studied by UV-visible absorption spectroscopy and fluorescence spec-

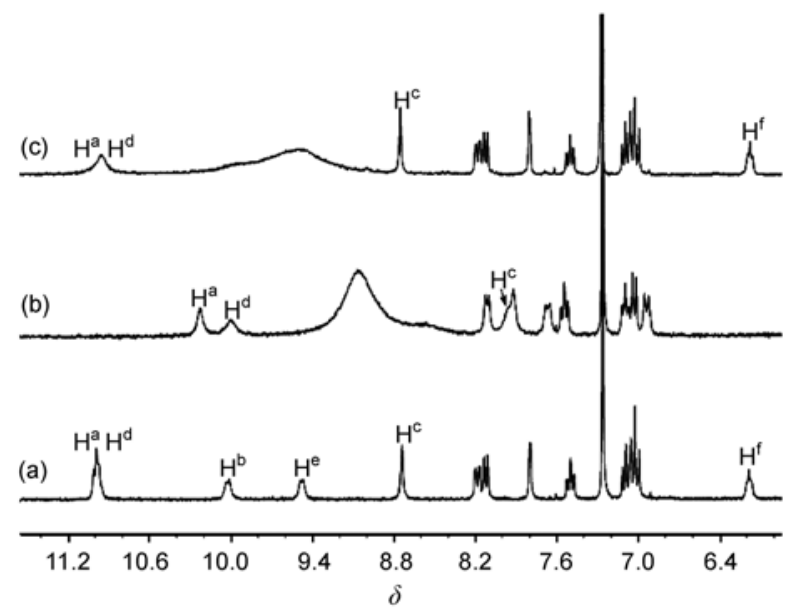

Figure 3 Partial ${ }^{1} \mathrm{H}$ NMR spectra of LMOG 1 in $\mathrm{CDCl}_{3}(300 \mathrm{MHz}, 298$ $\mathrm{K})$. (a) 1 (5.0 mmol/L); (b) after adding 10 equiv of TFA; (c) after adding 12 equiv of TEA troscopy. Compared with the corresponding dilute solution of 1 in $\mathrm{CH}_{2} \mathrm{Cl}_{2}\left(10^{-5} \mathrm{~mol} / \mathrm{L}\right)$, the gel of $\mathbf{1}$ showed a much broadened and red-shifted UV-vis absorption spectrum, which suggested that $\pi-\pi$ stacking interaction played an important role in the gel. In the fluorescence spectra, the solution of 1 in $\mathrm{CH}_{2} \mathrm{Cl}_{2}\left(10^{-4} \mathrm{~mol} / \mathrm{L}\right)$ exhibited relatively weak fluorescence emission (Figure 5). In contrast, the fluorescence emission intensity of $\mathbf{1}$ in the gel state was largely enhanced, which referred to the aggregation-induced emission (AIE) enhancement [43]. Meanwhile, the fluorescence maximum emission was red shifted by about $10 \mathrm{~nm}$ in the gel of $\mathbf{1}$. Combining with the UV-visible absorption spectra, it could be deduced that $\mathbf{1}$ formed J-aggregate in the gel, which was also a reason responsible for the fluorescence emission enhancement in the gel state relative to the solution of $\mathbf{1}$. Another reason may be that the formation of homoduplex via strong intermolecular hydrogen-bonding restricted the bond rotation of $\mathbf{1}$, and increased the rigidity and coplanarity of the backbones, and thus prohibited the nonradiative transitions to some extent. The AIE property may render the gel of $\mathbf{1}$ potentially applicable in the design of solid-state chemosensors.

To gain visual insight into the microscopic morphology of the organogels formed by $\mathbf{1}$, SEM and TEM were utilized to investigate the assembly structures (Figure 6). The SEM images of the free-dried gels formed by $\mathbf{1}$ in benzene and in methanol both showed thread-like fibrous structures with widths of tens of nanometers and lengths of up to tens of micrometers. These fibers further interlaced and selfassembled into three-dimensional networks, which could entrap solvent molecules in their interstices. The TEM images of the free-dried gels formed by $\mathbf{1}$ in benzene and in methanol also revealed the nano-fibrous structures. Moreover, the SEM and TEM images of the gels in other solvents including $\mathrm{CH}_{2} \mathrm{Cl}_{2}$, THF, toluene and ethanol, all revealed the similar morphologies, which indicated that the selfassembly of LMOG 1 in the gels was independent on the gelation solvents.

The xerogel formed by $\mathbf{1}$ in $\mathrm{CH}_{2} \mathrm{Cl}_{2}$ was then studied by PXRD (Figure 7), which provided further insight into the self-assembly of the gelators. The diffraction pattern showed 


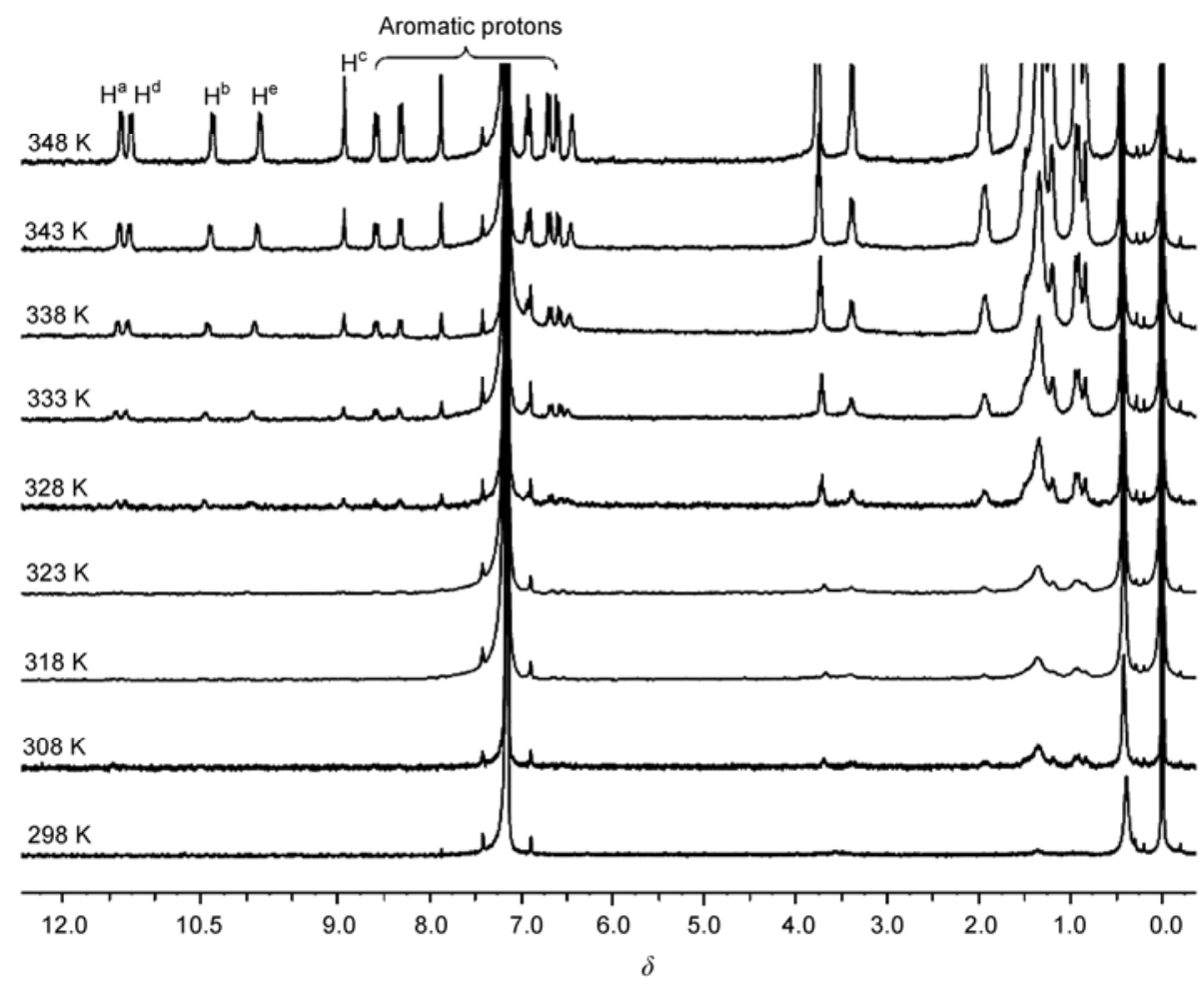

Figure 4 Variable-temperature ${ }^{1} \mathrm{H}$ NMR spectra of LMOG 1 in benzene- $d_{6}(5.0 \mathrm{mmol} / \mathrm{L})$.

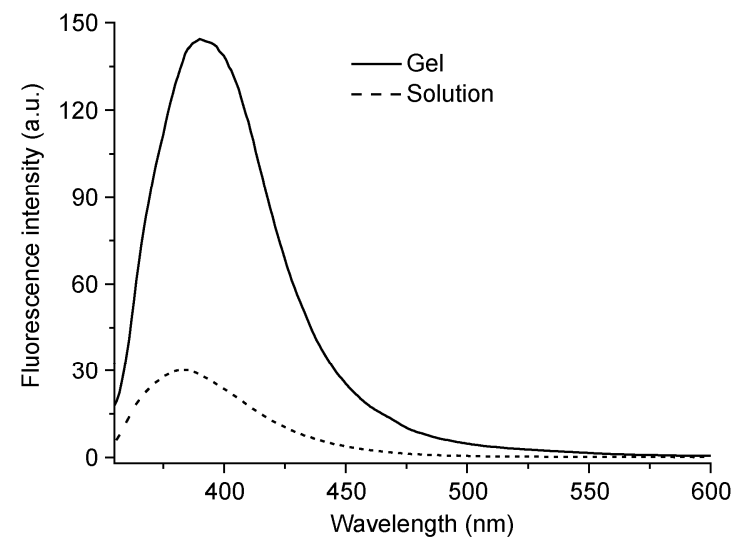

Figure 5 Fluorescence spectra $\left(\lambda_{\mathrm{ex}}=343 \mathrm{~nm}\right)$ of gel 1 and solution 1 $\left(10^{-4} \mathrm{~mol} / \mathrm{L}\right)$ in $\mathrm{CH}_{2} \mathrm{Cl}_{2}$.

two sharp strong diffractions at 22.0 and $15.8 \AA$ in the small angle region, which fully corresponded to the length (23.6 $\AA$ ) and width $(16.7 \AA)$ of the hydrogen-bonded homoduplex $\mathbf{1 \cdot 1}$ obtained by the density functional theory (DFT) calculation. These data confirmed that the hydrogen-bonded duplexes were indeed the basic units for assembling into supramolecular networks. The diffractogram also revealed a sharp strong diffraction at $14.0 \AA$, suggesting a well-defined layer structure [44]. And a $d$-spacing of $3.85 \AA$ consistent with the $\pi-\pi$ stacking distance was shown, which supported that $\pi-\pi$ stacking interaction was another driving force in the gel formation of $\mathbf{1}$. In addition, the PXRD analyses of the xerogels of $\mathbf{1}$ from benzene or methanol afforded the same information.

Based on the above experiment results, we rationally proposed the gelation mechanism of LMOG 1. First, the eight intermolecular tricenter hydrogen-bonding interactions ensured that gelator 1 paired into the sequence-specific homoduplex. With their largely planar surfaces, the duplexes then aggregated into two dimensional lamellar structures via $\pi-\pi$ stacking interactions. The long alkyl chains of $\mathbf{1}$ further promoted the 2D layers to assemble into three dimensional networks through van der Waals interactions. Consequently, the entangled fibers were formed and entrapped the solvent molecules in their interstices, and thereby led to the formation of organogels.

\section{Conclusions}

We found that the amidourea-based homoduplex as a super LMOG could form stable gels in wide-tested solvents. And the reversible gel to solution transition was responsive to heat/cool and acid/base stimuli. The organogels of $\mathbf{1}$ were extensively investigated by ${ }^{1} \mathrm{H}$ NMR, UV-visible absorption spectroscopy, fluorescence spectroscopy, SEM, TEM and PXRD. Based on these data, we rationally proposed the gelation mechanism of LMOG 1. The hydrogen-bonded homoduplexes served as the basic assembling units, and further aggregated into three dimensional networks via $\pi-\pi$ stacking and van der Waals interactions, which consequently led to the entangled fibers for the gel formation. The results 

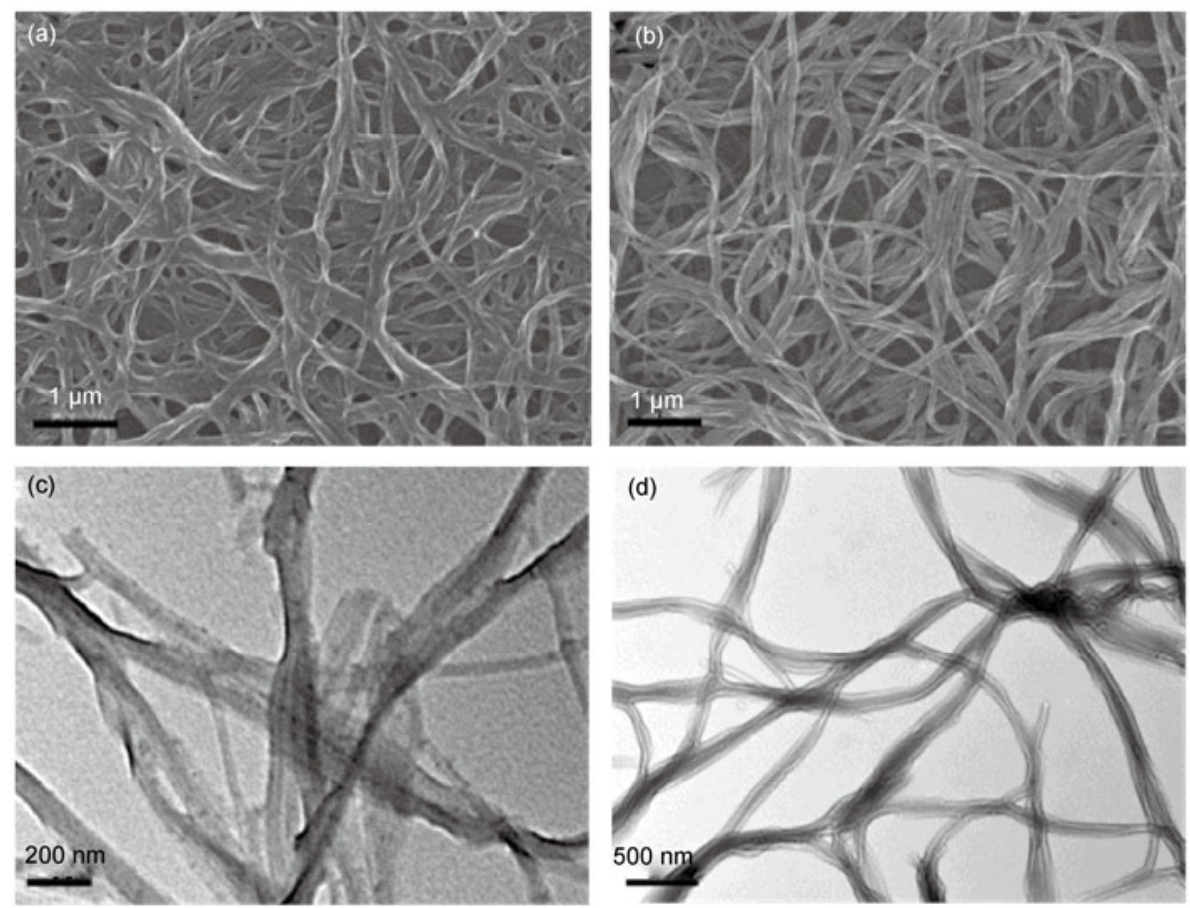

Figure 6 SEM images of the free-dried gel formed by 1 in benzene (a), in methanol (b). TEM images of the free-dried gel formed by 1 in benzene (c), in methanol (d).

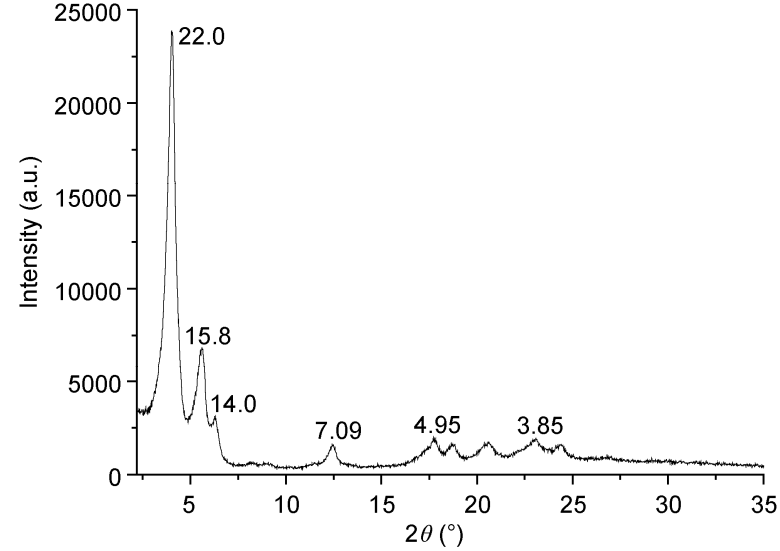

Figure 7 XRD pattern of the xerogel formed by 1 in $\mathrm{CH}_{2} \mathrm{Cl}_{2}$.

presented here may provide valuable insights into the gelation process, and promote the rational design of new organogelators.

This work was supported by the National Natural Science Foundation of China (91127009) and the National Basic Research Program of China (2011CB932501).

1 Terech P, Weiss R G. Low molecular mass gelators of organic liquids and the properties of their gels. Chem Rev, 1997, 97: 3133-3159

2 Terech P, Weiss R G. Molecular Gels: Materials with Self-Assembled Fibrillar Networks. Dordrecht: Springer, 2006

3 Fages F. Low molecular mass gelators. Top Curr Chem, 2005, 256: $1-273$

4 Steed J W. Supramolecular gel chemistry: Developments over the last decade. Chem Commun, 2011, 47: 1379-1383

5 de Jong J J D, Lucas L N, Kellogg R M, et al. Reversible optical transcription of supramolecular chirality into molecular chirality. Science, 2004, 304: 278-281

6 Ajayaghosh A, Praveen V K, Vijayakumar C, et al. Molecular wire encapsulated into $\pi$ organogels: Efficient supramolecular lightharvesting antennae with color-tunable emission. Angew Chem Int Ed, 2007, 46: 6260-6265

7 Hirst A R, Escuder B, Miravet J F, et al. High-tech applications of self-assembling supramolecular nanostructured gel-phase materials: From regenerative medicine to electronic devices. Angew Chem Int Ed, 2008, 47: 8002-8018

8 Tao T, Assenmacher W, Peterlik H, et al. An air-stable organometallic low-molecular-mass gelator: Synthesis, aggregation, and catalytic application of a palladium pincer complex. Angew Chem Int Ed, 2007, 46: 6368-6371

9 George M, Weiss R G. Molecular organogels. Soft matter comprised of low-molecular-mass organic gelators and organic liquids. Acc Chem Res, 2006, 39: 489-497

10 Wang G T, Lin J B, Jiang X K, et al. Cholesterol-appended aromatic imine organogelators: A case study of gelation-driven component selection. Langmuir, 2009, 25: 8414-8418

$11 \mathrm{Hu}$ J, Zhang M, Ju Y. A simple oleanlic acid derivative as potent organogelator. Soft Matter, 2009, 5: 4971-4974

$12 \mathrm{Lu} \mathrm{J} \mathrm{R,} \mathrm{Hu} \mathrm{J,} \mathrm{Song} \mathrm{Y,} \mathrm{et} \mathrm{al.} \mathrm{A} \mathrm{new} \mathrm{dual-responsive} \mathrm{organogel} \mathrm{based} \mathrm{on}$ uracil-appended glycyrrhetinic acid. Org Lett, 2011, 13: 3372-3375

13 Suzuki M, Hanabusa K. L-Lysine-based low-molecular-weight gelators. Chem Soc Rev, 2009, 38: 967-975

14 Wang T Y, Li Y G, Liu M H. Gelation and self-assembly of glutamate bolaamphiphiles with hybrid linkers: Effect of the aromatic ring and alkyl spacers. Soft Matter, 2009, 5: 1066-1073

15 Tian Y, Zhang L, Duan P F, et al. Fabrication of organogels composed from carbon nanotubes through a supramolecular approach. New J Chem, 2010, 34: 2847-2852

16 Cai W, Wang G T, Xu Y X, et al. Vesicles and organogels from foldamers: A solvent-modulated self-assembling process. J Am Chem Soc, 2008, 130: 6936-6937 
17 Cai W, Wang G T, Du P, et al. Foldamer organogels: A circular dichroism study of glucose-mediated dynamic helicity induction and amplification. J Am Chem Soc, 2008, 130: 13450-13459

18 Yang Y, Chen T, Xiang J F, et al. Mutual responsive hydrazide-based low-molecular-mass organic gelators: Probing gelation on the molecular level. Chem Eur J, 2008, 14: 5742-5746

19 Liu J W, Yang Y, Chen C F, et al. Novel anion-tuning supramolecular gels with dual-channel response: Reversible sol-gel transition and color changes. Langmuir, 2010, 26: 9040-9044

20 Liu J W, Ma J T, Chen C F. Structure-property relationship of a class of efficient organogelators and their multistimuli responsiveness. Tetrahedron, 2011, 67: 85-91

21 Wang C, Zhang D Q, Zhu D B. A low-molecular-mass gelator with an electroactive tetrathiafulvalene group: Tuning the gel formation by charge-transfer interaction and oxidation. J Am Chem Soc, 2005, 127: $16372-16373$

22 Wang C, Zhang D Q, Xiang J F, et al. New organogels based on an anthracene derivative with one urea group and its photodimer: Fluorescence enhancement after gelation. Langmuir, 2007, 23: 9195-9200

23 Steed J W. Anion-tuned supramolecular gels: A natural evolution from urea supramolecular chemistry. Chem Soc Rev, 2010, 39: 3686-3699

24 Ajayaghosh A, Praveen V K. $\pi$-organogels of self-assembled p-phenylenevinylenes: Soft materials with distinct size, shape, and functions. Acc Chem Res, 2007, 40: 644-656

25 Ajayaghosh A, Praveen V K, Vijayakumar C. Organogels as scaffolds for excitation energy transfer and light harvesting. Chem Soc Rev, 2008, 37: 109-122

26 Wurthner F, Bauer C, Stepanenko V, et al. A black perylene bisimide super gelator with an unexpected J-type absorption band. Adv Mater, 2008, 20: 1695-1698

27 Prasanthkumar S, Saeki A, Seki S, et al. Solution phase epitaxial self-assembly and high charge-carrier mobility nanofibers of semiconducting molecular gelators. J Am Chem Soc, 2010, 132: 88668867

28 Piepenbrock M O M, Lloyd G O, Clarke N, et al. Metal- and anion-binding supramolecular gels. Chem Rev, 2010, 110: 1960-2004

29 Sobczuk A A, Tamaru S, Shinkai S. New strategy for controlling the oligothiophene aggregation mode utilizing the gel-to-sol phase transition induced by crown-alkali metal interactions. Chem Commun, 2011, 47: 3093-3095

30 Saez J A, Escuder B, Miravet J F. Selective catechol-triggered supramolecular gel disassembly. Chem Commun, 2010, 46: 7996-
7998

31 Chen Q, Zhang D Q, Zhang G X, et al. New cholesterol-based gelators with maleimide unit and the relevant michael adducts: Chemoresponsive organogels. Langmuir, 2009, 25: 11436-11441

32 Lee D C, McGrath K K, Jang K. Nanofibers of asymmetrically substituted bisphenazine through organogelation and their acid sensing properties. Chem Commun, 2008, 44: 3636-3638

33 Li Y G, Liu K Q, Liu J, et al. Amino acid derivatives of cholesterol as "latent" organogelators with hydrogen chloride as a protonation reagent. Langmuir, 2006, 22: 7016-7020

34 Yang X Y, Zhang G X, Zhang D Q. Stimuli responsive gels based on low molecular weight gelators. J Mater Chem, 2012, 22: 38-50

35 Wang C, Chen Q, Sun F, et al. Multistimuli responsive organogels based on a new gelator featuring tetrathiafulvalene and azobenzene groups: reversible tuning of the gel-sol transition by redox reactions and light irradiation. J Am Chem Soc, 2010, 132: 3092-3096

36 Chen Q, Feng Y, Zhang D Q, et al. Light-triggered self-assembly of a spiropyran-functionalized dendron into nano-/micrometer-sized particles and photoresponsive organogel with switchable fluorescence. Adv Funct Mater, 2010, 20: 36-42

37 Chen Q, Zhang D Q, Zhang G X, et al. Multicolor tunable emission from organogels containing tetraphenylethene, perylenediimide, and spiropyran derivatives. Adv Funct Mater, 2010, 20: 3244-3251

38 Yoshio M, Shoji Y, Tochigi Y, et al. Electric field-assisted alignment of self-assembled fibers composed of hydrogen-bonded molecules having laterally fluorinated mesogens. J Am Chem Soc, 2009, 131: 6763-6767

39 Cravotto G, Cintas P. Molecular self-assembly and patterning induced by sound waves. The case of gelation. Chem Soc Rev, 2009, 38: 2684-2697

40 Li Y G, Wang T Y, Liu M H. Ultrasound induced formation of organogel from a glutamic dendron. Tetrahedron, 2007, 63: 7468-7473

41 Cao R K, Zhou J J, Wang W, et al. Oligoamide duplexes as organogelators. Org Lett, 2010, 12: 2958-2961

42 Chu W J, Yang Y, Chen C F. Multiple hydrogen-bond-mediated molecular duplexes based on the self-complementary amidourea motif. Org Lett, 2010, 12: 3156-3159

43 Hong Y N, Lam J W Y, Tang B Z. Aggregation-induced emission. Chem Soc Rev, 2011, 40: 5361-5388

44 Qu S N, Zhao L J, Yu Z X, et al. Nanoparticles, helical fibers, and nanoribbons of an achiral twin-tapered bi-1,3,4-oxadiazole derivative with strong fluorescence. Langmuir, 2009, 25: 1713-1717

Open Access This article is distributed under the terms of the Creative Commons Attribution License which permits any use, distribution, and reproduction in any medium, provided the original author(s) and source are credited. 